\title{
Preventing Formation of Reticulon 3 Immunoreactive Dystrophic Neurites Improves Cognitive Function in Mice
}

\author{
Qi Shi, ${ }^{\star}$ Marguerite Prior, ${ }^{\star}$ Xiangdong Zhou, Xiaoying Tang, Wanxia He, Xiangyou Hu, and Riqiang Yan \\ Department of Neurosciences, Lerner Research Institute, Cleveland Clinic Foundation, Cleveland, Ohio 44195
}

\begin{abstract}
Neuritic dystrophy is one of the important pathological features associated with amyloid plaques in Alzheimer's disease (AD) and age-dependent neuronal dysfunctions. We reported previously that reticulon-3 (RTN3) immunoreactive dystrophic neurites (RIDNs) are abundantly present in the hippocampus of AD patients, in AD mouse models, and in aged wild-type mice. Transgenic mice overexpressing the human RTN3 transgene spontaneously develop RIDNs in their hippocampi, and the formation of RIDNs correlates with the appearance of RTN3 aggregation. To further elucidate whether the formation of RIDNs is reversible, we generated transgenic mice expressing wild-type human RTN3 under the control of a tetracycline-responsive promoter. Treatment with doxycycline for 2 months effectively turned off expression of the human RTN3 transgene, confirming the inducible nature of the system. However, the formation of hippocampal RIDNs was dependent on whether the transgene was turned off before or after the formation of RTN3 aggregates. When transgenic human RTN3 expression was turned off at young age, formation of RIDNs was essentially eliminated compared with the vehicle-treated transgenic mice. More importantly, a fear conditioning study demonstrated that contextual associative learning and memory in inducible transgenic mice was improved if the density of RIDNs was lowered. Additional mechanistic study suggested that a reduction in BDNF levels in transgenic mice might contribute to the reduced learning and memory in transgenic mice overexpressing RTN3. Hence, we conclude that age-dependent RIDNs cannot be effectively cleared once they have formed, and we postulate that successful prevention of RIDN formation should be initiated before RTN3 aggregation.
\end{abstract}

\section{Introduction}

The reticulon (RTN) protein family consists of four members, RTN1 to RTN4. RTN4, also known as Nogo, has been shown to have a putative role in the inhibition of neurite outgrowth (Strittmatter, 2002; Schwab, 2004). Among the RTN family, the C-terminal domain of RTN proteins, encoded by five exons, is known as the reticulon homology domain (RHD), whereas the $\mathrm{N}$-terminal domain is completely divergent (Oertle et al., 2003; Yan et al., 2006). Topological studies indicate that the RHD, containing two long hydrophobic stretches (31-34 amino acids) separated by a loop region of $\sim 66$ aa (Fournier et al., 2002), directs RTN proteins (RTNs) to adopt $\omega$-shape membrane topology with both ends facing the intracellular space (Voeltz et al., 2006; He et al., 2007). RTNs on the membrane surface are found to interact with Alzheimer's $\beta$-secretase (BACE1) and negatively modulate BACE1 enzymatic activity by reducing $\beta$-amyloid (A $\beta$ ) levels (He et al., 2004; Murayama et al., 2006; Shi et al., 2009b).

Received May 21, 2012; revised Nov. 27, 2012; accepted Dec. 17, 2012.

Author contributions: Q.S., M.P., and R.Y. designed research; Q.S., M.P., X.Z., X.T., W.H., and X.H. performed research; Q.S., M.P., and R.Y. analyzed data; Q.S., M.P., and R.Y. wrote the paper.

This work is partially supported by National Institutes of Health Grant AG025493 (R.Y.) and Alzheimer's Association Award NPSPAD-10-174543 (R.Y.). A postdoctoral fellowship from American Health Association Foundation (A2008-627) is awarded to M.P.

${ }^{*} Q$.S. and M.P. contributed equally to this work.

Correspondence should be addressed to Dr. Riqiang Yan, Department of Neurosciences, Lerner Research Institute, The Cleveland Clinic Foundation, 9500 Euclid Avenue, Cleveland, OH 44195. E-mail: yanr@ccf.org.

DOI:10.1523/JNEUROSCI.2445-12.2013

Copyright $\odot 2013$ the authors $\quad 0270-6474 / 13 / 333059-08 \$ 15.00 / 0$
While exploring the in vivo role of RTN in Alzheimer's disease (AD) pathogenesis, we discovered that overexpression of neuronal RTN3 in transgenic (Tg) mice resulted in the spontaneous development of RTN3 immunoreactive dystrophic neurites (RIDNs) in their hippocampi (Hu et al., 2007). Morphologically, RIDNs exhibit abnormally swollen neurites and resemble the previously described dystrophic neurites marked by ubiquitin, GAP-43, or neurofilament in AD brains (Rifenburg and Perry, 1995). RIDNs seen in young RTN3 Tg mice are similar to those found in aged normal mouse hippocampi, indicating that the occurrence of RIDNs in RTN3 Tg mice represents an acceleration of a naturally occurring event (Shi et al., 2009a). More importantly, we demonstrated that RIDNs are the most abundant type of dystrophic neurites in surrounding amyloid plaques in brains of $\mathrm{AD}$ patients (Hu et al., 2007). The underlying molecular cause of RIDNs is attributed to the aggregation of RTN3 (Hu et al., 2007). Because the presence of RIDNs in hippocampi of mouse models correlates with the reduction of dendritic spine density, long-term potentiation (LTP) and learning behavior in the Barnes maze test (Hu et al., 2007), it is postulated that the presence of RIDNs in $\mathrm{AD}$ brains contributes to the cognitive dysfunction seen in patients (Prior et al., 2010).

To determine whether the formation of RIDNs is reversible and whether a reduction in RTN3 aggregation could potentially ameliorate cognitive dysfunction in elderly and $\mathrm{AD}$ patients, we generated Tg mice expressing wild-type human RTN3 under the control of tetracycline (Tet) responsible element (TetOff promoter). We found that increased expression of the RTN3 transgene in the mouse forebrain facilitated the formation of RIDNs significantly earlier than in wild-type littermates. By manipulat- 
ing the expression of the transgene either before or after the formation of RIDNs, we were able to answer the question of whether reducing RTN3 levels would have a significant effect on the formation of RIDNs. We conclude that reducing RTN3 levels before RTN3 aggregation could significantly inhibit the formation of RIDNs and that RIDN density is correlated with impairments in learning and memory. We therefore postulate that targeted early inhibition of RTN3 aggregation has therapeutic potential for $\mathrm{AD}$ patients.

\section{Materials and Methods}

Mouse strains. Tet response element (TRE)CMV-hRTN3 Tg mice were generated in the laboratory. Briefly, the transgene of Tetresponsive $P h C M V^{*}-1$ promoter-hRTN3 was constructed by insertion of an hRTN3 cDNA into the pTRE2hyg plasmid vector (Clontech Laboratories) between BamHI and NotI in the multiple cloning site, which allows the expression of hRTN3 under the control of the Tet-responsive $\mathrm{PhCMV}^{*}-1$ promoter. A new PvuI site was created downstream of the $\beta$-globin poly(A) DNA sequence in the plasmid, which allowed us to isolate the DNA fragment of Tet-responsive $\mathrm{PhCMV}^{*}$-hRTN3- $\beta$-globin poly(A) from the plasmid by restriction enzyme digestion at XhoI and PvuI sites. The purified transgene DNA fragment was microinjected into the male pronuclei of fertilized mouse oocytes (B6C3F1). The oocytes were then implanted into the oviduct of pseudo-pregnant mothers. More than three founders were generated from the injection. The offspring were maintained by breeding to C57BL/6J mice. Their genotype was determined using Southern blotting and PCR. The PCR primers were $5^{\prime}$-CAGTCCCATTCCATCTCCTC- ${ }^{\prime}$ and $5^{\prime}$-CAATCGGGACACTGAAA ATG-3'. The probe for Southern blotting was synthesized using the PCR primers and the template of hRTN3 cDNA. CaMKII-trans-activator protein (tTA) Tg mice were purchased from The Jackson Laboratory and were bred with TRE-CMV-hRTN3 Tg mice (line 8) to produce compound mice, named RTN3TetOff. The compound RTN3TetOff mice expressed hRTN3 when the trans-activator tTA from CaMKII-tTA transgene bound to TRE and activated transcription from CMV-hRTN3. All mice in the study were maintained and used according to the protocols approved by the Institutional Animal Care and Use Committee at the Cleveland Clinic Foundation.

Reagents. Antibodies against calnexin (C4731) and $\beta$-actin (A5441) were purchased from Sigma-Aldrich. Antibodies R454 and R458 were generated by the laboratory (He et al., 2004). Antibody R454 exclusively recognizes the $\mathrm{N}$ terminus of human RTN3 protein, whereas antibody $\mathrm{R} 458$ recognizes the $\mathrm{C}$ termini of both human and mouse RTN3. Antibrain-derived neurotrophic factor (BDNF) antibody (sc546) was purchase from Santa Cruz Biotechnology. Alexa Fluor 488- and 568-labeled goat anti-rabbit secondary antibodies were purchased from Invitrogen. Doxycycline (Dox) was purchased from Sigma-Aldrich. The stock solution of Dox was made in $66.66 \mathrm{mg} / \mathrm{ml}$ and frozen in aliquot at $-20^{\circ} \mathrm{C}$. To turn off TRE-CMV-hRTN3 expression, the test group of mice was fed with Dox solution $(0.5 \mathrm{mg} / \mathrm{ml})$ freshly prepared with autoclaved tap water containing $2 \%$ sucrose. The feeding Dox solution was changed every 3-4 d and covered with light-preventive foil. Four to $12 \%$ Bis-Tris NuPage gels for Western blotting and reagents for PCR analysis were purchased from Invitrogen. Protease inhibitor cocktail tablets were purchased from Roche Biosciences.

Western blot analysis of mouse hippocampi. Mouse hippocampi were dissected from the mouse brain and frozen at $-80^{\circ} \mathrm{C}$. For Western blot- ting analysis, frozen dissected hippocampi were homogenized in a solution containing $50 \mathrm{~mm}$ Tris- $\mathrm{HCl}, \mathrm{pH} 7.5,150 \mathrm{~mm} \mathrm{NaCl}, 0.5 \% \mathrm{NP}-40$, RochR complete protease inhibitors $(1 \times)$, and phosphatase inhibitor $\mathrm{Na}_{3} \mathrm{VO}_{4}(0.1 \mathrm{~mm})$ on ice. Total proteins were extracted from the homogenates by agitating on a rotator for $30 \mathrm{~min}$ at $4^{\circ} \mathrm{C}$. After centrifugation at $15,000 \times g$ for $120 \mathrm{~min}$, supernatants were collected. Total protein concentrations of the supernatants were determined with BCA protein assay reagent (Pierce). Equal amounts of the supernatants ( $40 \mu \mathrm{g}$ of total protein) were resolved on $4-12 \%$ Bis-Tris NuPage gel, followed by standard Western blotting with antibodies specified in the text. Chemiluminescent signals for proteins on Western blots were scanned, and their integrated density values were calculated with a chemiluminescent imaging system (Alpha Innotech).

Immunofluorescence confocal microscopy and quantification. Immunofluorescence confocal microscopy experiments were performed as described previously (He et al., 2004). The right halves of mouse brains were sectioned in the sagittal plane at a $14 \mu \mathrm{m}$ thickness using a cryostat after $4 \%$ paraformaldehyde fixation and O.C.T. compound embedding. Brain sections were stored at $-80^{\circ} \mathrm{C}$. After three washes in PBS $(1 \times)$, brain sections were incubated in $0.3 \%$ Triton X-100 in PBS $(1 \times)$ for 30 min. After additional washes in PBS $(1 \times)$, the sections were blocked in $5 \%$ goat serum in PBS $(1 \times)$ for $30 \mathrm{~min}$. Then the sections were incubated in primary antibody against RTN3 overnight. The sections were then washed in PBS $(1 \times)$ three times and incubated in secondary antibody goat anti-mouse IgG conjugated with either Alexa Fluor 488 or Alexa Fluor 568. The fluorescence images were examined and captured with a Leica SP5 confocal microscope. We manually determined the counts of RIDNs in evenly spaced six hippocampi per mouse brain. Group means were calculated based on the counts of individual animals.

Fear conditioning assay. Contextual and cued memory of mice were examined in a fear conditioning chamber (Med Associates) using Ponder's protocol (Ponder et al., 2008). Each mouse was trained in the same 

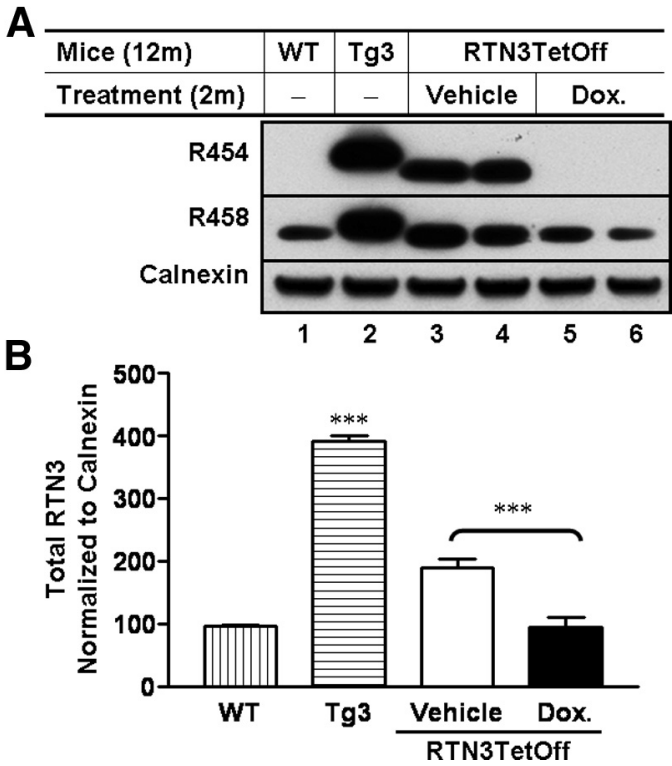

Figure 2. RTN3 transgene was effectively turned off by Dox treatment. $A$, Equal amounts of hippocampal proteins from indicated genotypes of 12 -month-old $(12 \mathrm{~m})$ mice were analyzed by Western blotting. RTN3TetOff mice were treated with either Dox or $2 \%$ sucrose (vehicle) for 2 months (2m). Antibody R454 exclusively recognizes the N terminus of Tg RTN3 with human origin. Antibody R458 recognizes both ( termini of Tg human RTN3 and endogenous mouse RTN3. In the representative Western blot image, wild-type (WT) and Tg RTN3 served as controls (lanes 1,2). The proteins from RTN3TetOff mice treated with vehicle are shown in lanes 3 and 4 , whereas the proteins from RTN3TetOff mice treated with Dox are shown in lanes 5 and $6 . \boldsymbol{B}$, The relative protein levels of RTN3 over the loading control calnexin in each genotype group were shown in bar graphs. $\operatorname{Tg}$ RTN3 mice expressed $\operatorname{~g~human~RTN3~constitutively~at~a~level~fourfold~}$ higher than that of wild-type mice, whereas the total hippocampal RTN3 protein of human and mouse in RTN3Tet0ff mice was increased by twofold compared with wild-type mice ( $n=4$, $189.3 \pm 14.3$ vs $94.2 \pm 15.4,{ }^{* * *} p<0.001$, Tukey's multiple comparison test). Two-month Dox treatment completely turned off expression of RTN3 transgene in RTN3TetOff mice as shown in Western blotting with R454.

conditioning chamber. On the day of conditioning (day 1), each mouse was individually placed in the chamber and allowed to explore the chamber for $3 \mathrm{~min}$. After the exploration, the mice were exposed to a conditioned stimulus (a tone of $3 \mathrm{kHz}$ and $85 \mathrm{~dB}$ for $30 \mathrm{~s}$ ), followed by an unconditioned stimulus (an electric footshock of $0.7 \mathrm{~mA}$ for $2 \mathrm{~s}$ ) that was delivered during the last $2 \mathrm{~s}$ of the conditioned stimulus. The conditioning was repeated after a $30 \mathrm{~s}$ interval. On the second day (day 2), the mice were returned to the same chamber to measure freezing in response to the context. To determine contextual memory, freezing time was recorded by a video camera for $150 \mathrm{~s}$, starting from $30 \mathrm{~s}$ after entry into the chamber. Neither tone nor footshock was delivered. On the third day, the same mice were again placed into the same chamber with significantly altered context, including different walls, floor, and background odor. Two conditioned stimuli (two $30 \mathrm{~s}$ tones) were presented to the mice in the same way as those presented on day 1 , in the absence of the footshock. Freezing during the presentation of tones was recorded by video camera to assess tone-mediated cued memory. Fear conditioning data were acquired using software Freezeframe and analyzed using software Freezeview (Coulbourn Instruments and Actimetrics).

Determination of BDNF levels by ELISA. BDNF levels were measured with BDNF Emax Immunoassay System (Promega), a kit showing no significant cross-reactivity with other neurotrophic factors (NGF and neurotrophins 3 and 4/5) as described previously (Szapacs et al., 2004). Briefly, proteins were extracted from the hippocampal and cortical regions from wild-type and RTN3 Tg mice by sonication in the following lysis buffer: $100 \mathrm{~mm}$ PIPES, pH 7.0, $500 \mathrm{~mm} \mathrm{NaCl}, 0.5 \% \mathrm{NP}-40,0.1 \%$ $\mathrm{NaN} 3,2 \%$ BSA, 2 mm EDTA.Na2 $-2 \mathrm{H}_{2} \mathrm{O}$, and $3 \times$ protease inhibitor cocktail. The crude extracts were centrifuged for $30 \mathrm{~min}$ at $13,000 \mathrm{rpm}$ at $4^{\circ} \mathrm{C}$ to remove insoluble materials, and total protein concentration of supernatants was measured by Bio-Rad protein assay. Equal amounts of

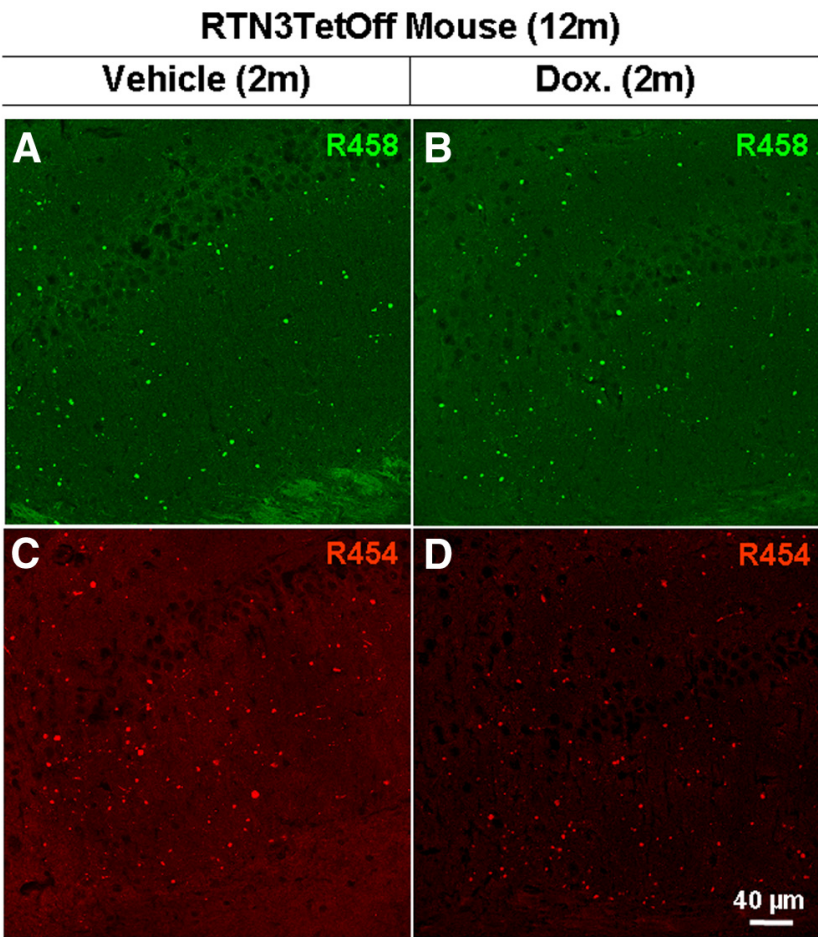

Figure 3. RIDNs remained in the hippocampus of RTN3TetOff mice after Dox treatment. Sagittal mouse brain sections $(14 \mu \mathrm{m})$ were reacted with antibody R458 and anti-rabbit Alexa Fluor 488 secondary antibody $(\boldsymbol{A}, \boldsymbol{B})$ or with antibody R454 and anti-rabbit Alexa Fluor 568 secondary antibody $(\boldsymbol{C}, \boldsymbol{D})$. RIDNs in hippocampal CA1 region were visible by using confocal immunofluorescence microscopy. Scale bar, $40 \mu \mathrm{m}$. As shown in the confocal images of hippocampal CA1 region, the number of RIDNs was not significantly reduced in Dox-treated RTN3TetOff mice $(\boldsymbol{B}, \boldsymbol{D})$ compared with the vehicle-treated littermates $(\boldsymbol{A}, \boldsymbol{C}) .2 \mathrm{~m}$, Two months; $12 \mathrm{~m}, 12$ months.

protein extracts from each sample were used for measuring of BDNF by ELISA according to the procedures described in the protocol.

Statistical analyses. For comparison between two groups at a single time point, an unpaired $t$ test was performed. When comparing multiple groups, one-way ANOVA followed by a Tukey's post hoc test was used. All statistical analysis was conducted using GraphPad Prism software. Data are expressed as group mean \pm SEM, and significance of difference is indicated as ${ }^{\star} p<0.05,{ }^{* *} p<0.01$, and ${ }^{* * *} p<0.001$.

\section{Results}

\section{Characterization of Tg mice overexpressing RTN3}

To achieve inducible expression of RTN3 in vivo, we generated Tg mice expressing human RTN3 cDNA under the control of inducible TRE (Fig. 1A). The assembled construct was then linearized by enzymatic digestions, and the gel-purified plasmid DNA was injected into mouse pronuclei (B6C3F1 strain). After screening 107 pups, we recovered 13 positive founder mice, which were verified by both PCR genotyping (Fig. $1 B$ ) and Southern blotting (data not shown). Although 13 founder lines of Tg mice were generated, we found that most of them had similar levels of the transgene integrated into the mouse genome (data not shown). Therefore, four lines of mice were chosen to further breed with $\mathrm{Tg}$ mice expressing Tet-controlled tTA driven by CaMKII promoter (Tg-CaMK-tTA). By examining the brain lysates from the offspring carrying both RTN3 and tTA, we further validated that RTN3/CaMKII-tTA Tg mice (or called RTN3TetOff mice) indeed produced human RTN3 protein, detected by antibody R454, which specifically reacts with the N-terminus-specific epitope of human, but not murine, RTN3 (Fig. 1C). Among four lines of RTN3TetOff Tg mice examined for RTN3 expression, we 
found that RTN3 levels among these lines did not vary significantly, and so the highest expressing line was therefore chosen for subsequent experiments.

Like the Tg mice constitutively expressing a myc-tagged RTN3 reported in our previous study ( $\mathrm{Hu}$ et al., 2007), RTN3TetOff Tg mice did not show obviously discernible growth defects (data not shown). RIDNs appeared to be detectable at the age of 5 months (data not shown), and the density of RIDNs at the age of 8 months was moderate. This is consistent with a previous report (Hu et al., 2007) that the density of RIDNs is highly age dependent and correlated with the expression level of RTN3 transgene.

\section{Inducible expression of RTN3 transgene to monitor \\ RTN3 aggregation}

To determine whether the formation of RIDNs is reversible, we first aged RTN3TetOff Tg mice to 10 months and then turned off the expression of the transgene by adding $0.5 \mathrm{mg} / \mathrm{ml}$ Dox, a more stable derivative of Tet, to the drinking water. Dox treatment for 2 months completely shut down the expression of human RTN3 because the human transgene was no longer detectable by antibody R454 (Fig. 2A). Because C-terminal RTN3 antibody R458 detects both human and mouse RTN3, we noticed that the total RTN3 level in the treated RTN3TetOff Tg mice was essentially comparable with that in wild-type controls (Fig. 2B).

Contrary to our expectations, the density of RIDNs in Doxtreated RTN3TetOff Tg mice was not visibly different from that of vehicle-treated RTN3TetOff Tg mice (Fig. $3 A, B$ ). Because the human RTN3-specific antibody R454 could also detect RIDNs in Dox-treated RTN3TetOff Tg mouse hippocampi, it indicated that the human RTN3 transgene in the RTN3 aggregates was not removed during the Dox treatment period (Fig. $3 C, D$ ). Additional quantification confirmed no significant alterations in RIDN density in the hippocampal region because total numbers of RIDNs between two genotypes of mice were not significant different $(1095 \pm 65.9$ RIDNs Dox-treated vs $1157 \pm 78.1$ in vehicle-treated sections, $n=4, p>0.1$, Student's $t$ test). Thus, RTN3 aggregates in the dystrophic neurites appear to be not readily degradable or cleared during a 2 month period in which there was a clear reduction of the RTN3 transgene. It is possible that the proteasome or protein degradation system in the neuritic region is less efficient.

Formation of RIDNs is prevented by reducing RTN3 levels at early time points

Because RTN3 aggregates are not readily removed after their formation, we asked whether the formation of RIDNs is preventable if RTN3 levels are reduced just before the formation of RTN3 aggregates. We found that RTN3TetOff Tg mice began to produce RIDNs at $\sim 5$ months of age. We therefore treated RTN3TetOff Tg mice beginning at the age of 5 months with Dox and continued treatment for 4 months. A 4 month treatment of RTN3TetOff Tg mice with Dox completely turned off the expression of the RTN3 transgene (Fig. 4A,B). When RIDNs were imaged by confocal microscopy, we found that antibody R454 failed to detect RIDNs in Dox-treated RTN3TetOff Tg mice (Fig. 5, compare $C, A$ ), whereas vehicle-treated RTN3TetOff Tg mice at the age of 9 months produced a low density of RIDNs, detectable by both R454 and R458 (Fig. 5B,E). Quantification of RIDN density further confirmed that RIDNs were mainly present in vehicle-treated RTN3TetOff Tg mice (Fig. 5G). Together, these data demonstrate that reducing RTN3 transgene expression before the formation of RTN3 aggregates can prevent the formation of RIDNs.

\section{Reduced BACE1 processing of APP by overexpressing RTN3} Our previous studies indicate that RTN3 is a negative modulator of BACE1, and its inhibitory activity is adversely affected when it aggregates in the hippocampus of Tg RTN3 mice (Shi et al., 2009b). Because the RTN3TetOff mice formed RIDNs in the CA1 region at a modest level, we asked whether elevated expression of RTN3 would affect BACE1 activity. We performed standard Western blotting analysis on total protein extracts from hippocampal homogenates of both the 4-month vehicle-treated and 4-month Dox-treated RTN3TetOff mice to determine the effect of RTN3 on BACE1 activity. We found that the endogenous fulllength APP level was higher in vehicle-treated mice than that in Dox-treated mice (Fig. 6A). Quantification showed that APP 

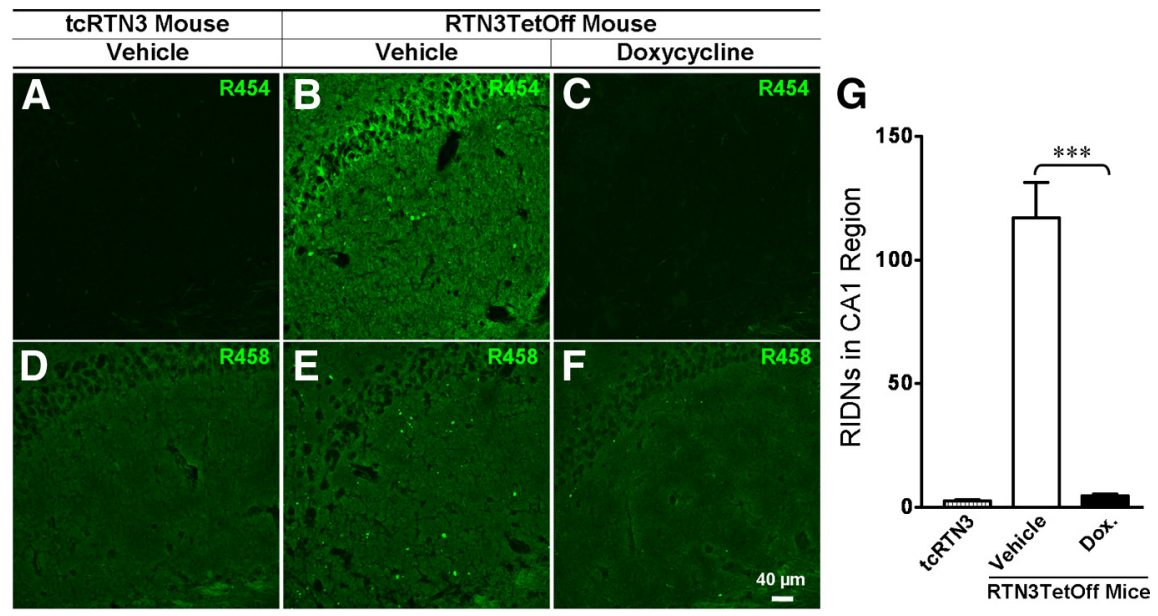

Figure 5. Elimination of RIDNs in RTN3TetOff mice with early Dox treatment. Sagittal mouse brain sections were labeled by antibody R454 (A-C) or antibody R458 (D-F). Anti-rabbit Alexa Fluor 488 secondary is the secondary antibody. Antibody R458 recognizes both Tg RTN3 and endogenous mouse RTN3. To detect the presence of only RTN3 transgene in RIDNs, antibody R454 was used for detection. When antibody R458 was applied, hippocampal RIDNs were easily detected in the vehicle-treated RTN3Tet0ff mice, but only sparse hippocampal RIDNs were detected in both the tcRTN3 mice $(\boldsymbol{D})$ and the Dox-treated RTN3Tet0ff mice $(\boldsymbol{F})$. Scale bar, $40 \mu \mathrm{m} . \mathbf{G}$, The hippocampal RIDN counts in the vehicle-treated RTN3TetOff mice were significantly higher than in the tcRTN3 mice ( $118 \pm 21.5$ vs $2.6 \pm 0.7$ in 6 sections per mouse, $n=5, p<0.01$, Tukey's multiple comparison test). After 4 months of Dox treatment, hippocampal RIDN counts were significantly reduced ( $4.6 \pm 1.5$ in sections per mouse, $n=5, p<0.01$, Tukey's multiple comparison test).

A

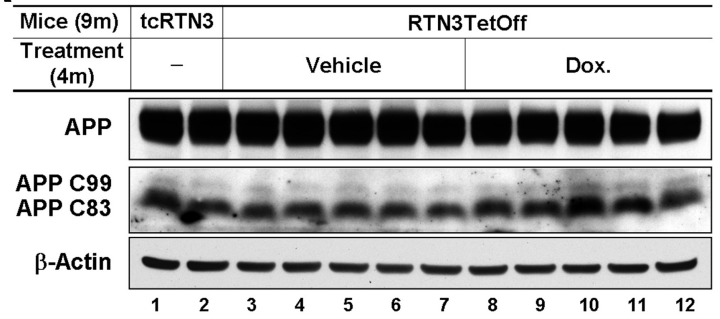

B

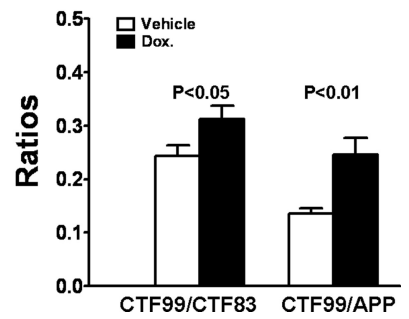

Figure 6. Reduction of APP processing by overexpressed RTN3. A, Hippocampal protein lysates were analyzed by Western blotting with antibody specific to APP (terminus (antibody A8717). APP (99 is the BACE1-cleaved product from APP, whereas APP C83 is the product from $\alpha$-secretase cleavage of APP. $\beta$-Actin antibody was used to verify the loading. $\boldsymbol{B}$, Relative BACE1 activity was assessed by the ratio of $C 99$ over $(83$ or 99 over APP. Statistic significance was calculated by one-way ANOVA statistical analysis, which showed significance ( $p<0.05$ or $p<0.01, n=5$ ). $4 \mathrm{~m}$, Four months; $9 \mathrm{~m}, 9$ months.

processing in vehicle-treated mice (RTN3 levels were higher as shown in Fig. $6 A$ ) was $\sim 13 \%$ lower than that in the Dox-treated mice $(38.71 \pm 0.7918$ vs $33.82 \pm 1.875$, respectively, $n=5, p<$ 0.05; Fig. $6 B)$.

To determine whether this change resulted from APP processing by $\alpha$-secretase or $\beta$-secretase, the ratio of APP CTF99/ APP CTF83 was calculated based on the Western blotting data. We found the ratio of CTF99/CTF83 was lowered by $22 \%$ in the vehicle-treated mice compared with Dox-treated mice $(0.2437 \pm 0.01990$ vs $0.3119 \pm 0.02608$, respectively, $n=5$, $p<0.05$; Fig. 6C), suggesting a small reduction in the $\beta$-secretase activity in the vehicle-treated mice. We also found that the ratio of APP CTF99 over full-length APP was significantly lowered in vehicle-treated mice compared with Doxtreated mice $(0.1357 \pm 0.01048$ vs $0.2460 \pm 0.03152$, respectively, $n=5, p<0.01$; Fig. $6 D)$. Thus, our data confirm that elevated levels of RTN3 monomer have inhibitory effects on BACE1 activity, consistent with recent findings in animal models (Shi et al., 2009b; Araki et al., 2013).
The density of RIDNs in the

hippocampus correlates with impaired learning and memory

The hippocampus is known to play an important role in the acquisition and consolidation of contextual fear memory (Kim and Fanselow, 1992; Phillips and LeDoux, 1992; Lee and Kesner, 2004; Daumas et al., 2005). Because RIDNs are mostly enriched in the mouse hippocampal CA1 region and less in the $\mathrm{CA} 3$ region, we asked whether the occurrence of RIDNs affects the formation of contextual memory. To address this, a fear conditioning test was conducted in RTN3TetOff Tg mice with or without Dox treatment for 4 months, beginning at the age of 5 months. As demonstrated previously, Dox treatment prevents the formation of RIDNs in RTN3TetOff Tg mice (Fig. 5). Fear conditioning was used to measure hippocampaldependent associative learning. In this test, the associative learning of a cue (sound) or a context (environment) with a brief aversive stimulus (electric shock) was measured by analyzing the freezing response of the mice. Before the training, both groups of mice had normal levels of freezing, similar to those of wild-type mice (Fig. 7A, Pre-con). On day 1 , mice were placed in the fear conditioning chamber for contextual learning by exposure to a sound, followed by a footshock. During the training period, we observed no difference in the percentage of freezing between these two groups ( $t$ test, $p>0.1, n=$ 10). On day 2 , mice were placed back in the chamber without exposure to sound or shock for the same length of time as the previous day. Context-dependent freezing was measured according to published procedures (Ponder et al., 2008) to evaluate the learned aversion of an animal for the environment associated with the mild aversive stimulus. We found that the Dox-treated RTN3TetOff Tg mice showed significantly increased freezing time in response to the context, which was much greater than that in the vehicle-treated RTN3TetOff Tg mice (Fig. 7A, Context, $t$ test, $p<$ 0.001). This demonstrated that preventing the formation of hippocampal RIDNs significantly improved contextual learning and memory capability in these mice. More interestingly, RIDN density was positively correlated with the severity of hippocampusdependent contextual memory deficits (Fig. 7B). On day 3, mice were placed in a context-altered chamber, in which they were exposed to the same sound at the same time points as day 1 . We measured their freezing in response to the tone, a test that is less dependent on hippocampal function but more related to the amygdala (Phillips and LeDoux, 1992). Mice in both groups (with or without Dox treatment) showed dramatically increased freezing to the tone in a context-altered chamber (Fig. 7A, Tone). Although Dox-treated animals showed an even higher percentage of freezing than vehicle-treated RTN3TetOff Tg mice, the difference was not statistically significant ( $t$ test, $p>0.1$ ). This suggests that the tonemediated cued learning and memory was less associated with the 

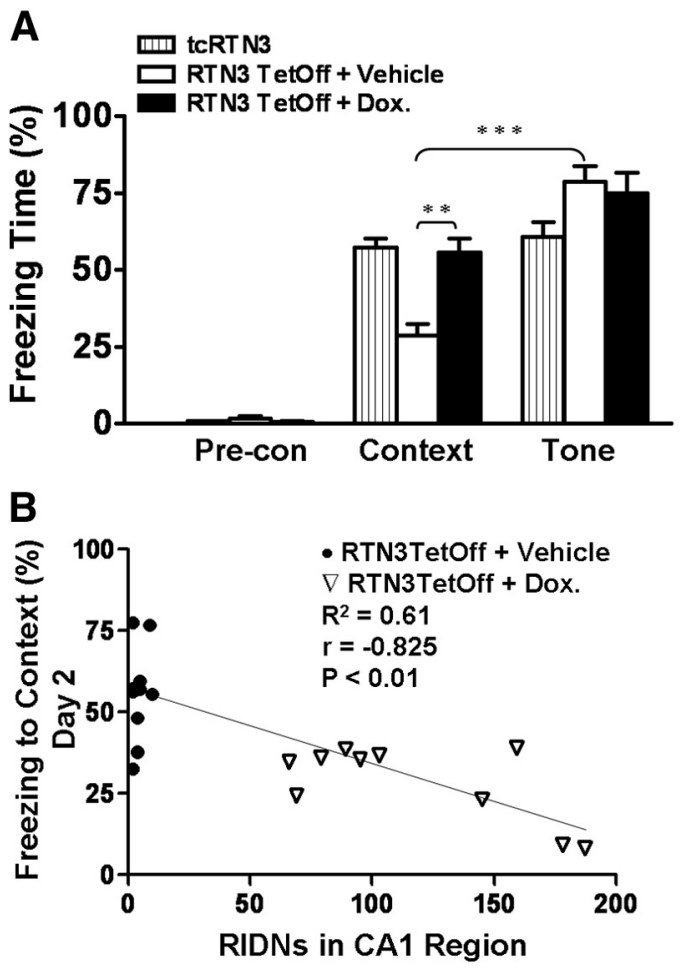

Figure 7. Reducing formation of RIDNs improves contextual associative learning and memory in RTN3TetOff mice. $A$, Fear conditioning assay of learning and memory included a testing procedure of $3 \mathrm{~d}$ in a fear conditioning chamber. There was no difference in the percentage of freezing time before conditioning on day 1 (Pre-con). On day 2, contextual associative learning and memory of the mice were analyzed. Percentage of total freeze time of mice on day 2 was recorded as an ability of contextual associative learning and memory. The percentage of total freeze time was significantly improved from $24.5 \pm 5.5$ to $63.2 \pm 5.0 \%$ after treatment of RTN3Tet0ff mice with Dox $(n=12, p<0.01)$. $\boldsymbol{B}$, The relationship between the RIDN counts and the contextual associated learning and memory was examined by statistical correlation analysis. Percentage of total freeze was plotted against the counts of RIDNs in hippocampal CA1 region. Their correlation coefficient $r=-0.816, R^{2}=0.666(n=12, p<0.01)$, indicating a negative correlation between the hippocampal RIDN formation and the contextual associated learning and memory in the mice.

density of hippocampal RIDNs. Together, these data show that the higher the density of RIDNs, the greater the impairment of contextual memory in this mouse model.

Reduced BDNF levels attributable to the formation of RIDNs We demonstrated previously that hippocampal RIDNs disrupt dendritic arborization and reduce the density of dendritic spines in Tg RTN3 mice (Hu et al., 2007; Shi et al., 2009a). Such a structural alteration correlates with impaired learning and memory. To understand the molecular mechanisms underlying the impairment of learning and memory, we postulated that RIDNinduced structural alterations in the hippocampal CA1 region may disrupt the Schaffer collateral pathway via regulatory neurotrophic factors. Among many neurotrophic factors, BDNF is the most plausible candidate because it is transported in and released from both axons and dendrites, as well as primarily stored in presynaptic vesicles (Adachi et al., 2005; Dieni et al., 2012), which are likely affected by the local presence of RIDNs. In addition, BDNF plays important roles not only in neuritic arborization (Cohen-Cory et al., 2010) but also in memory-related LTP (Egan et al., 2003; Zakharenko et al., 2003; Aicardi et al., 2004; Pang et al., 2004).
A
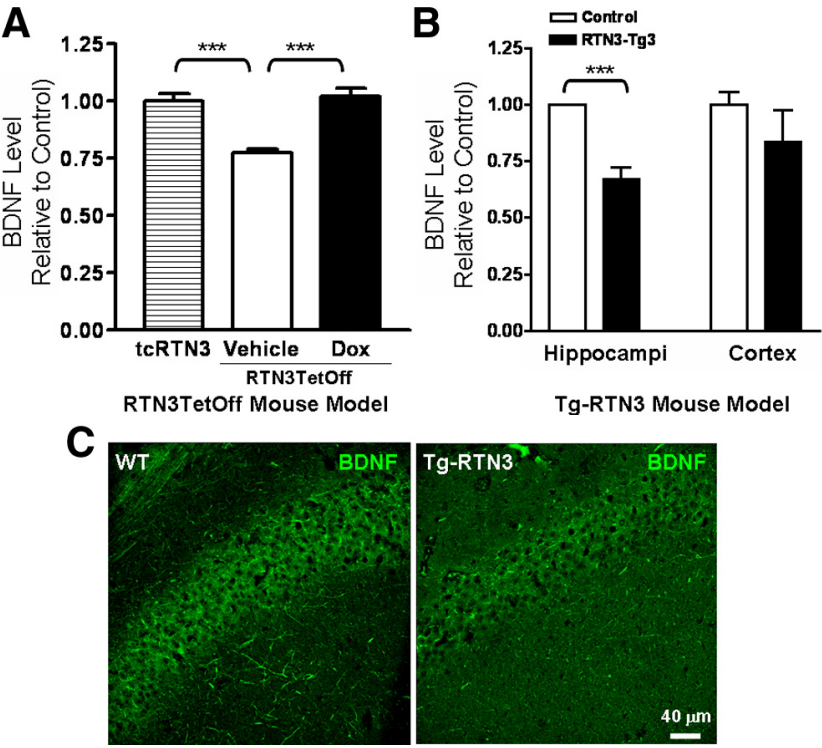

Figure 8. Reduction of BDNF in the hippocampus of the RTN3 Tg mice. ELISA was performed to determine the levels of BDNF in protein extracts that were prepared from either RTN3TetOff mice $(\boldsymbol{A})$ or Tg RTN3 mice $(\boldsymbol{B})$ and their littermate controls. The levels of hippocampal BDNF were significantly reduced in hippocampi of both mouse models ( $n=6$ in RTN3TetOff mice group and $n=6$ in Tg RTN3 mice group; ${ }^{* * *} p<0.01$ ). However, the levels of cortical BDNF between $\operatorname{Tg}$ RTN3 mice and their control littermates showed no statistical difference $(n=6 ; p>0.05)$. All results are presented as a mean $\pm S E$. $C$, Immuno-confocal microscopy revealed that the positive BDNF immunity in the CA1 pyramidal neurons of the control mice (WT), whereas the BDNF immunity was mostly reduced in the Tg RTN3 mice. The mouse anti-BDNF antibody and the goat anti-mouse Alexa Fluor 488 antibody were used to label sagittal mouse brain sections $(14 \mu \mathrm{m})$ in the immunofluorescent study.

We determined the level of BDNF by a sensitive ELISA method (Szapacs et al., 2004; Ma et al., 2012). The total level of BDNF was reduced by $\sim 22.8 \%$ in the hippocampus of RTN3TetOff mice compared with their single Tg tcRTN3 littermates $(n=6, p<0.01$; Fig. $8 A)$. To validate this reduction further, we also measured BDNF levels in RTN3 Tg mouse hippocampus in which more abundant RIDNs are formed. Our results showed a greater reduction of BDNF (by $\sim 33 \%, n=6, p<$ 0.05; Fig. $8 B$ ). Consistently, confocal staining also showed a clear reduction of BDNF staining in CA1 pyramidal neurons and processes (Fig. 8C). Interestingly, the level of BDNF in the cortex of RTN3 Tg mice was only slightly affected, which is consistent with the rarity of cortical RIDNs and the absence of abnormal dendritic arbors in the 9-month-old RTN3 Tg mice. Hence, our data imply that there is a correlation between RIDN density and reduction of BDNF.

\section{Discussion}

For the past decade, pharmaceutical interventions for $\mathrm{AD}$ have been centered primarily on decreasing amyloid deposition in brain (Weiner and Selkoe, 2002; Gandy et al., 2003; Chow et al., 2010). Active vaccination of $\mathrm{AD}$ patients with $\mathrm{A} \beta$ peptides, an approach that has previously received great attention, showed a marked reduction of amyloid deposition (Tarawneh and Holtzman, 2009). However, cognitive function in these treated patients showed little improvement. Because aggregation of $\mathrm{A} \beta$ peptides appears to facilitate the formation of dystrophic neurites, which are found to surround amyloid deposits together with reactive astrocytes and activated microglia, it is plausible that removing amyloid deposition may not be sufficient to reduce other pathological features, such as dystrophic neurites in $\mathrm{AD}$ 
brains. This study provides evidence that RIDNs, which contain RTN3 aggregates, are not readily removable and that the continuing presence of RIDNs may hinder the complete reversal of cognitive dysfunction in $\mathrm{AD}$ patients, even in cases of dramatic reductions in amyloid plaques. It is likely that preventing the formation of dystrophic neurites or RIDNs will be a necessary therapeutic strategy for the successful treatment of $\mathrm{AD}$ patients.

RIDNs appear to be the most abundant dystrophic neurites found surrounding amyloid plaques in brains of $\mathrm{AD}$ patients $(\mathrm{Hu}$ et al., 2007). In addition, the age-dependent occurrence of RIDNs in mice has also been documented (Shi et al., 2009a). Because the presence of RIDNs can cause a reduction of dendritic spine density and cognitive dysfunctions, it is possible that aging-dependent memory decline, encountered in normal elderly people (Winocur and Moscovitch, 1990; Gallagher and Rapp, 1997), may also be attributable to the high density of RIDNs. The occurrence of RIDNs correlates with the abnormal aggregation of RTN3 (Hu et al., 2007). In this study, we examined whether the formation of RIDNs or abnormal RTN3 aggregation is reversible by using an inducible expression system in a mouse model. Our results indicate that the formation of RIDNs is not readily reversible.

Fear conditioning assays have been widely used to evaluate hippocampal-dependent contextual learning and memory in $\mathrm{AD}$ mouse models (Corcoran et al., 2002; Oddo et al., 2003). Previous studies have revealed that the hippocampus is involved in contextual, but not cued, fear conditioning, whereas the amygdala is involved in both contextual and cued fear conditioning (Phillips and LeDoux, 1992; Johansen et al., 2011). In the present study, prevention of RIDN formation in hippocampus alleviated impairment in contextual learning and memory in the compound $\mathrm{Tg}$ mice. RIDN formation had no effect on cued learning and memory. There was no difference in pretraining activity between the two groups of mice, indicating that, in the absence of the aversive stimulus, Dox itself did not alter the mobility of the mice. The pretraining mobile activity and the level of the cued memory of RTN3TetOff mice of both groups are similar to those of wildtype C57BL/6J mice (Stiedl et al., 2000). We showed here that the density of RIDNs present in the hippocampus inversely correlated with cognitive function in our animals. Our results also suggest that inhibition of RTN3 aggregation should be targeted early, before the formation of RIDNs.

It should be noted that reduction of BDNF has been reported in brains of AD patients (Phillips et al., 1991; Laske et al., 2006). Aggregation of $A \beta$ has been linked previously to the reduction of BDNF (Tong et al., 2004). Our study suggests that RTN3 aggregation in RIDNs can also contribute to the reduction (Fig. 8). In the CNS, BDNF is synthesized and secreted by neurons from soma in a constitutive manner and from nerve terminals, predominantly dendritic postsynaptic terminals, in a regulatory manner (Lessmann et al., 2003; Brigadski et al., 2005; Santos et al., 2010). BDNF can stimulate TrkB receptor signaling pathways on both postsynaptic and presynaptic terminals via autocrine and paracrine pathways (McAllister, 2002). Although how RTN3 aggregation causes a reduction of BDNF remains to be determined, we have already known that the presence of RIDNs impairs axonal terminus as demonstrated in our previous EM experiments (Hu et al., 2007). In addition, we observed a reduction of BDNF mRNA level in Tg RTN3 mouse hippocampi (data not shown). Our future biochemical assays are aimed to explore the underlying consequence.

As demonstrated in a current model, the physiological action of BDNF on both dendrites and axons is to promote their branching and synaptic connection (McAllister et al., 1999; Cohen-Cory et al., 2010). Consistent with the important role of BDNF in the control of dendritic arborization and synaptic connection, the impaired dendritic arborization and reduction of spine density in the CA1 region of Tg RTN3 mice have been reported previously (Hu et al., 2007; Shi et al., 2009a), and correlated changes were also seen in RTN3TetOff mice (data not shown). These structural alterations significantly reduced formation of synapses between the dendrites of pyramidal neurons in CA1 and afferent axons, such as Schaffer collaterals and the entorhinal cortex layer III fibers. Hence, a reduction in BDNF signaling and synaptic connections in association with the presence of RIDNs could account for a significant reduction of LTP (Hu et al., 2007). Together, severe neuritic dystrophy causes the reduction of BDNF levels, which in turn impairs cognitive function.

Hippocampal BACE1 activity in the RTN3TetOff mice was clearly lowered when the RTN3 level was modestly reduced (Fig. 6). If the RTN3 level was returned to the level comparable with the wild-type controls as a result of 4 month Dox treatment, BACE1 activity appears to revert to the control level. In this TetOff mouse model, the density of RIDNs was significantly lower than that of Tg RTN3 mice, in which higher expression of RTN3 also facilitates the formation of a large amount of RTN3 aggregates (Hu et al., 2007). Our result appears in line with a recent observation that a small increase of RTN3 in mouse neurons (by $\sim 40 \%$ ) decreases amyloid deposition by $\sim 50 \%$ (Araki et al., 2013). Hence, future studies should target to a small elevation of RTN3 but just enough so as to prevent RTN3 aggregation. Because age-dependent RIDNs cannot be effectively cleared once they have formed, we postulate that successful prevention of RIDN formation should be initiated before RTN3 aggregation.

\section{References}

Adachi N, Kohara K, Tsumoto T (2005) Difference in trafficking of brainderived neurotrophic factor between axons and dendrites of cortical neurons, revealed by live-cell imaging. BMC Neurosci 6:42. CrossRef Medline

Aicardi G, Argilli E, Cappello S, Santi S, Riccio M, Thoenen H, Canossa M (2004) Induction of long-term potentiation and depression is reflected by corresponding changes in secretion of endogenous brain-derived neurotrophic factor. Proc Natl Acad Sci U S A 101:15788-15792. CrossRef Medline

Araki W, Oda A, Motoki K, Hattori K, Itoh M, Yuasa S, Konishi Y, Shin RW, Tamaoka A, Ogino K (2013) Reduction of $\beta$-amyloid accumulation by reticulon 3 in transgenic mice. Curr Alzheimer Res, in press.

Brigadski T, Hartmann M, Lessmann V (2005) Differential vesicular targeting and time course of synaptic secretion of the mammalian neurotrophins. J Neurosci 25:7601-7614. CrossRef Medline

Chow VW, Savonenko AV, Melnikova T, Kim H, Price DL, Li T, Wong PC (2010) Modeling an anti-amyloid combination therapy for Alzheimer's disease. Sci Transl Med 2:13ra1. CrossRef Medline

Cohen-Cory S, Kidane AH, Shirkey NJ, Marshak S (2010) Brain-derived neurotrophic factor and the development of structural neuronal connectivity. Dev Neurobiol 70:271-288. CrossRef Medline

Corcoran KA, Lu Y, Turner RS, Maren S (2002) Overexpression of hAPPswe impairs rewarded alternation and contextual fear conditioning in a transgenic mouse model of Alzheimer's disease. Learn Mem 9:243252. CrossRef Medline

Daumas S, Halley H, Francés B, Lassalle JM (2005) Encoding, consolidation, and retrieval of contextual memory: differential involvement of dorsal CA3 and CA1 hippocampal subregions. Learn Mem 12:375-382. CrossRef Medline

Dieni S, Matsumoto T, Dekkers M, Rauskolb S, Ionescu MS, Deogracias R, Gundelfinger ED, Kojima M, Nestel S, Frotscher M, Barde YA (2012) BDNF and its pro-peptide are stored in presynaptic dense core vesicles in brain neurons. J Cell Biol 196:775-788. CrossRef Medline

Egan MF, Kojima M, Callicott JH, Goldberg TE, Kolachana BS, Bertolino A, Zaitsev E, Gold B, Goldman D, Dean M, Lu B, Weinberger DR (2003) The BDNF val66met polymorphism affects activity-dependent secre- 
tion of BDNF and human memory and hippocampal function. Cell 112:257-269. CrossRef Medline

Fournier AE, GrandPr é T, Gould G, Wang X, Strittmatter SM (2002) Nogo and the Nogo-66 receptor. Prog Brain Res 137:361-369. CrossRef Medline

Gallagher M, Rapp PR (1997) The use of animal models to study the effects of aging on cognition. Annu Rev Psychol 48:339-370. CrossRef Medline

Gandy S, Martins RN, Buxbaum J (2003) Molecular and cellular basis for anti-amyloid therapy in Alzheimer disease. Alzheimer Dis Assoc Disord 17:259-266. CrossRef Medline

He W, Lu Y, Qahwash I, Hu XY, Chang A, Yan R (2004) Reticulon family members modulate BACE1 activity and amyloid-beta peptide generation. Nat Med 10:959-965. CrossRef Medline

He W, Shi Q, Hu X, Yan R (2007) The membrane topology of RTN3 and its effect on binding of RTN3 to BACE1. J Biol Chem 282:29144-29151. CrossRef Medline

Hu X, Shi Q, Zhou X, He W, Yi H, Yin X, Gearing M, Levey A, Yan R (2007) Transgenic mice overexpressing reticulon 3 develop neuritic abnormalities. EMBO J 26:2755-2767. CrossRef Medline

Johansen JP, Cain CK, Ostroff LE, LeDoux JE (2011) Molecular mechanisms of fear learning and memory. Cell 147:509-524. CrossRef Medline

Kim JJ, Fanselow MS (1992) Modality-specific retrograde amnesia of fear. Science 256:675-677. CrossRef Medline

Laske C, Stransky E, Leyhe T, Eschweiler GW, Wittorf A, Richartz E, Bartels M, Buchkremer G, Schott K (2006) Stage-dependent BDNF serum concentrations in Alzheimer's disease. J Neural Transm 113:1217-1224. CrossRef Medline

Lee I, Kesner RP (2004) Differential contributions of dorsal hippocampal subregions to memory acquisition and retrieval in contextual fearconditioning. Hippocampus 14:301-310. CrossRef Medline

Lessmann V, Gottmann K, Malcangio M (2003) Neurotrophin secretion: current facts and future prospects. Prog Neurobiol 69:341-374. CrossRef Medline

Ma B, Savas JN, Chao MV, Tanese N (2012) Quantitative analysis of BDNF/ TrkB protein and mRNA in cortical and striatal neurons using alphatubulin as a normalization factor. Cytometry A 81:704-717. CrossRef Medline

McAllister AK (2002) Spatially restricted actions of BDNF. Neuron 36:549550. CrossRef Medline

McAllister AK, Katz LC, Lo DC (1999) Neurotrophins and synaptic plasticity. Annu Rev Neurosci 22:295-318. CrossRef Medline

Murayama KS, Kametani F, Saito S, Kume H, Akiyama H, Araki W (2006) Reticulons RTN3 and RTN4-B/C interact with BACE1 and inhibit its ability to produce amyloid beta-protein. Eur J Neurosci 24:1237-1244. CrossRef Medline

Oddo S, Caccamo A, Shepherd JD, Murphy MP, Golde TE, Kayed R, Metherate R, Mattson MP, Akbari Y, LaFerla FM (2003) Triple-transgenic model of Alzheimer's disease with plaques and tangles: intracellular Abeta and synaptic dysfunction. Neuron 39:409-421. CrossRef Medline

Oertle T, Klinger M, Stuermer CA, Schwab ME (2003) A reticular rhapsody: phylogenic evolution and nomenclature of the RTN/Nogo gene family. FASEB J 17:1238-1247. CrossRef Medline

Pang PT, Teng HK, Zaitsev E, Woo NT, Sakata K, Zhen S, Teng KK, Yung WH, Hempstead BL, Lu B (2004) Cleavage of proBDNF by tPA/plasmin is essential for long-term hippocampal plasticity. Science 306:487-491. CrossRef Medline

Phillips HS, Hains JM, Armanini M, Laramee GR, Johnson SA, Winslow JW (1991) BDNF mRNA is decreased in the hippocampus of individuals with Alzheimer's disease. Neuron 7:695-702. CrossRef Medline
Phillips RG, LeDoux JE (1992) Differential contribution of amygdala and hippocampus to cued and contextual fear conditioning. Behav Neurosci 106:274-285. CrossRef Medline

Ponder CA, Huded CP, Munoz MB, Gulden FO, Gilliam TC, Palmer AA (2008) Rapid selection response for contextual fear conditioning in a cross between C57BL/6J and A/J: behavioral, QTL and gene expression analysis. Behav Genet 38:277-291. CrossRef Medline

Prior M, Shi Q, Hu X, He W, Levey A, Yan R (2010) RTN/Nogo in forming Alzheimer's neuritic plaques. Neurosci Biobehav Rev 34:1201-1206. CrossRef Medline

Rifenburg RP, Perry G (1995) Dystrophic neurites define diffuse as well as core-containing senile plaques in Alzheimer's disease. Neurodegeneration 4:235-237. Medline

Santos AR, Comprido D, Duarte CB (2010) Regulation of local translation at the synapse by BDNF. Prog Neurobiol 92:505-516. CrossRef Medline

Schwab ME (2004) Nogo and axon regeneration. Curr Opin Neurobiol 14: 118-124. CrossRef Medline

Shi Q, Hu X, Prior M, Yan R (2009a) The occurrence of aging-dependent reticulon 3 immunoreactive dystrophic neurites decreases cognitive function. J Neurosci 29:5108-5115. CrossRef Medline

Shi Q, Prior M, He W, Tang X, Hu X, Yan R (2009b) Reduced amyloid deposition in mice overexpressing RTN3 is adversely affected by preformed dystrophic neurites. J Neurosci 29:9163-9173. CrossRef Medline

Stiedl O, Misane I, Spiess J, Ogren SO (2000) Involvement of the 5-HT1A receptors in classical fear conditioning in C57BL/6J mice. J Neurosci 20: 8515-8527. Medline

Strittmatter SM (2002) Modulation of axonal regeneration in neurodegenerative disease: focus on Nogo. J Mol Neurosci 19:117-121. CrossRef Medline

Szapacs ME, Mathews TA, Tessarollo L, Ernest Lyons W, Mamounas LA, Andrews AM (2004) Exploring the relationship between serotonin and brain-derived neurotrophic factor: analysis of BDNF protein and extraneuronal 5-HT in mice with reduced serotonin transporter or BDNF expression. J Neurosci Methods 140:81-92. CrossRef Medline

Tarawneh R, Holtzman DM (2009) Critical issues for successful immunotherapy in Alzheimer's disease: development of biomarkers and methods for early detection and intervention. CNS Neurol Disord Drug Targets 8:144-159. CrossRef Medline

Tong L, Balazs R, Thornton PL, Cotman CW (2004) Beta-amyloid peptide at sublethal concentrations downregulates brain-derived neurotrophic factor functions in cultured cortical neurons. J Neurosci 24:6799-6809. CrossRef Medline

Voeltz GK, Prinz WA, Shibata Y, Rist JM, Rapoport TA (2006) A class of membrane proteins shaping the tubular endoplasmic reticulum. Cell 124: 573-586. CrossRef Medline

Weiner HL, Selkoe DJ (2002) Inflammation and therapeutic vaccination in CNS diseases. Nature 420:879-884. CrossRef Medline

Winocur G, Moscovitch M (1990) Hippocampal and prefrontal cortex contributions to learning and memory: analysis of lesion and aging effects on maze learning in rats. Behav Neurosci 104:544-551. CrossRef Medline

Yan R, Shi Q, Hu X, Zhou X (2006) Reticulon proteins: emerging players in neurodegenerative diseases. Cell Mol Life Sci 63:877-889. CrossRef Medline

Zakharenko SS, Patterson SL, Dragatsis I, Zeitlin SO, Siegelbaum SA, Kandel ER, Morozov A (2003) Presynaptic BDNF required for a presynaptic but not postsynaptic component of LTP at hippocampal CA1-CA3 synapses. Neuron 39:975-990. CrossRef Medline 